\title{
Conflict and Reconciliation of Binary Opposition in A Passage to India and A Passage to England
}

By Mahmoda Khaton Siddika

International Islamic University Chittagong

Abstract- The well-known myth of binary- England and India creates a conflict for the contrastive attitude in E. M. Forster's A Passage to India and Nirad C Chaudhuri's travelogue A Passage to England. The binary opposition of Anglo-Indian as colonizers and Indians as colonized leads to another set of binary, whitecolored, and civilized-primitive in A Passage to India. This binary contradicts each other to form them in another set of binary, controller-controlled during the British imperial rule in India. The contrastive structure is in the form of conflict reflected in their outlook, behavior, and lifestyle in this novel. On the other hand, by an eight-week-journey in western countries, Chaudhuri, as an Indian in England, exposes what he observes in the west together with the reality of India in the travelogue. He recognizes the social binaries upholded by Jacques Derrida in A Passage to England. Chaudhuri in his book has executed this binary sense as England-India, British-Indians possessing two independent entities of the world. The two writers, through Hegel's dialectic process, place the binary opposition implanting Derrida's view. The article focuses on the nature of the conflict and tries to explore reconciliation of the conflicts based on the comparative analysis of two books.

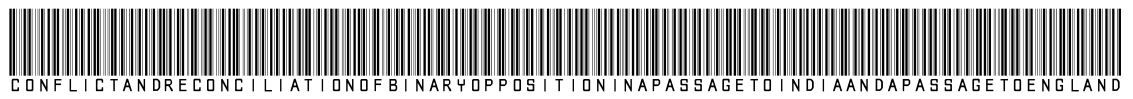

Strictly as per the compliance and regulations of:

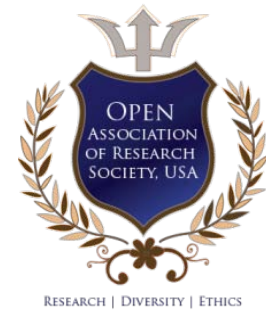

(C) 2021. Mahmoda Khaton Siddika. This is a research/review paper, distributed under the terms of the Creative Commons Attribution-Noncommercial 3.0 Unported License http://creativecommons.org/licenses/by-nc/3.0/), permitting all non-commercial use, distribution, and reproduction in any medium, provided the original work is properly cited. 


\title{
Conflict and Reconciliation of Binary Opposition in A Passage to India and A Passage to England
}

\author{
Mahmoda Khaton Siddika
}

Abstract- The well-known myth of binary- England and India creates a conflict for the contrastive attitude in $\mathrm{E}$. $\mathrm{M}$. Forster's $A$ Passage to India and Nirad C Chaudhuri's travelogue $A$ Passage to England. The binary opposition of Anglo-Indian as colonizers and Indians as colonized leads to another set of binary, white-colored, and civilized-primitive in $A$ Passage to India. This binary contradicts each other to form them in another set of binary, controller-controlled during the British imperial rule in India. The contrastive structure is in the form of conflict reflected in their outlook, behavior, and lifestyle in this novel. On the other hand, by an eight-week-journey in western countries, Chaudhuri, as an Indian in England, exposes what he observes in the west together with the reality of India in the travelogue. He recognizes the social binaries upholded by Jacques Derrida in $A$ Passage to England. Chaudhuri in his book has executed this binary sense as England-India, British-Indians possessing two independent entities of the world. The two writers, through Hegel's dialectic process, place the binary opposition implanting Derrida's view. The article focuses on the nature of the conflict and tries to explore reconciliation of the conflicts based on the comparative analysis of two books.

\section{INTRODUCTION}

F orster, in his novel A Passage to India, starts his narration showing the central problem for the gaps and differences with many views in the Mosque part of the novel. The most glaring gap is between Indian and Anglo-Indian. Chandrapore has two sectionsthe native states and the English city station. From these places, the town looks different. The City Station shares with the city only the "overarching sky" (32). AngloIndians occupy the City Station and restrict Indians from entering. They hold this place as a central point to rule the Indians, that is an alienated place from other parts of the city. But this part cannot separate the natural encompassing sky of the globe. This setting shows the fundamental differences between them, indicating binary sense. Moreover, it is screened from Indian Chandrapore behind the exuberant vegetation, meaning that the Anglo-Indian world is cut off from the Indian society. Like the setting of the novel, all through the development of the plot prevails an opposition which shows conflicts over culture, relationship, behavior for possessing binary oppositions of Indians and AngloIndians. This binary sense, Anglo-Indian and Indian,

Author: Assistant Professor of English. Center for University Requirement Courses, International Islamic University Chittagong, Bangladesh.e-mail: nazu_eng@yahoo.com moves through Anglo- Indian dealings as thesis and Indian attitude as an antithesis. Conversely, Chaudhuri, in every chapter of his travelogue, places an opposite view regarding binary sense- India and England by the process of thesis-antithesis-synthesis. Through this process, the writer himself attains an absolute sense regarding each idea. Using the binary opposition, the writer subtly exposes his Indianness. But in A Passage to India, the conflict for binary opposition is their relation of the controller and controlled, ruler and ruled. Though the context of these two books is different, these books deal with the same binary opposition- the English as colonizer and independent self and Indians as colonized and separate person. It is a matter of question that the conflict for binary opposition and a negative platform of reconciliation in A Passage to Indiacan turn into reconciliation by observing the lifestyles, thinking, and cultural differences in social binary in A Passage to England.

\section{Binary Opposition}

Macey (2001) points out that Binary opposition upholds a kind of myth that the world considers everything in a binary sense such as night and day, female and male, and so on. The French deconstructionist Jacques Derrida finds out the presence of binary sense in the social encounter. Derrida exposes that such opposition in the society creates 'a tacit hierarchy' that is, the one in this opposition holds superiority over the other one as Abrams and Harpham (1929) say. These dualities do not possess static condition, but flexible and they exchange their position. Between these dualities, Derrida makes this binary unstable. This binary in society lacks certainty and falls in the undecided condition. This opposition reestablishes itself.

The social binaries are visible in A Passage to India and A Passage to England. In A Passage to India, the duality of civilized-primitive, white-colored, and colonizer-colonized sense is evident. This binary opposes each other to rebuild them in new binary sense, controller-controlled. In A Passage to England, Nirad C. Chaudhuri follows the binary of idea-reality, Indians-British, and India-England. They oppose each other through different views. The binary opposition constitutes a collective binary of the two separate poles of the earth in this travelogue. This binary opposition is needed to explore the nature of the conflict of binary 
opposition between Indo-British integration. Thus, the thesis explores a bridge between two separate poles of the earth in these two literary works to explore reconciliation in the conflict of binary opposition.

\section{IiI. Anglo- Indian Dealings as Thesis in A PASSAGE TO INDIA}

As an Englishman, the writer starts his novel describing Chandrapore in India with nothing extraordinary except Marabar Cave, "the city of Chandrapore presents nothing extraordinary" (31). The Ganges offers nothing holiness, only full of rubbish on its bank, "scarcely distinguishable from the rubbish it deposits so freely" (31). The writer himself as an English shows his outlook regarding India negatively, as any other English shows in dealing with Indians. This negative outlook builds up a sense of alienation from Indians and the non-acceptance of Indians. So, they consider, "India isn't home" (54). They treat Indians in an official tune, "the only link he could be conscious of with an Indian was the official" (93). In their encounter, "every human act in the East is tainted with officialism" (188), and "where there is officialism every human relationship suffers" (212). People do not make a friendship of equals since all relationships are controlled by political reality. So, it is quite unbelievable for AngloIndian that "an Indian could be a channel of communication between two English people." (99). This kind of outlook is reflected in their dealings. The English woman treats the Indians as a queer body of the earth. They think of the Indians as a creeper, and Indians always try to find out a stick (the English man) to climb up. The English woman makes a barrier between them and Indians for only their non-acceptance attitude of Indians. Even an English nurse makes herself keep aloof from India for creating a disappointing situation to be "a nurse in a Native State" (48). Adela, a newcomer from England to India, takes India "as a frieze, never as a spirit" (66). During her journey to Marabar Cave, "AngloIndian life she had decided to endure" (148). At last, she admits that she sees India in what way the English place it.

In Anglo-Indians formed structure, they do not tolerate any break or hindrance. As an Englishman, Cyril Fielding winning the mind of Indians makes a gulf between his countrymen and himself as his countrymen regard him as a "disruptive force" (80) for his dangerous ideas, and he applies these ideas through the "interchange" (80) method. He feels comfortable to match with Indians, for which he has to give a price. Mr. Fielding chooses Dr. Aziz, an Indian Muslim, to develop his likings and relationship with him. His intimacy with Aziz is continuously haunted by a club's comment on making himself "cheap as usual" (126). After Adela's insult in the Marabar Caves, the Police Super tries to prove Aziz's character as a demoralized one by showing a woman's photograph in his pocket. Aziz is accused of the guilty of Adela's murder and rape at the same time. By withdrawing accusations of Dr. Aziz, Adela fells herself into the mass Indian shopkeeping class. As a result, her community except Fielding alienates her from them for their habit of non-acceptance of truth. Here, love, humanity, and reality become insignificant.

\section{Indian Attitude AS An Antithesis in A PASSAGE TO INDIA}

The English's non-acceptance of Indians creates misunderstanding and misconception between Indians and Anglo-Indians. The English people's behavior as a ruler makes the Indian hesitated to deal with the English people as Dr. Aziz feels hesitant to enter into the bungalow of Civil Surgeon. Whatever happens between Indo-British is explained negatively between Anglo-Indians and Indians. Their views are shaped based on any previous happening. Aziz's hesitation to enter Major Callendar's office creates a dilemma, "an Indian gentleman had driven up to an official's house" (39).

The English bridge party to integrate IndoBritish becomes an antithesis to widen the gulf between them because of doing nothing and showing their typical behavior towards Indians. Adela and Mrs. Moore try to avail any opportunity to converse with "friendly Indians" (62), but Indian women's lack of cooperation makes a hindrance. To Indians, "Bridge Party did well rather than harm" (64) and they analyze this with different impressions. They think that Anglo-Indians are rude to Indians which is a barrier to attach them smoothly. Indians attend any party of the English with a mind of happening a disaster. The collector organizes a party with Indians. Nawab Bahadur inspires all to attend. They attend with a prediction in their mind that "disaster may come" (73). At first, Dr. Aziz determines not to go to the English Party for his wife's death anniversary. He does not depend on English people for their inability to understand him and even they can mock him.

Indians always try to create a good impression on the English people doing positive works like proper time management accomplishing any work on time. They are busy with removing prejudice that "Indians are incapable of responsibility" (145). Moreover, Indians receive the other country's people as a guest giving remarkable hospitality. Any discomfort of a guest is like tearing his soul. Dr. Aziz's honest thinking of the expedition to Marabar Caves to honor guests not to forget the Indians becomes ironic at the end of this expedition. He is arrested for insulting Miss Quested in the Marabar Cave. After relieving from accusation, all Indians are happy to win the battle against their enemy, the English. 
V. Thesis and Antithesis in $A$ PASSAGE TO ENGLAND

\section{a) The Cultural Life}

English cultural life, an enriching aspect of English life signified the intellectual and artistic pride, is connected with religion. English people think of Christianity for its noteworthy contribution to the upgrading of their civilization. General people prefer spending in the university town to living in the seaside resort. The common visitors show their actual devotion to the chapel belonging to the same sensational divine spirit.

Hindu religion lacks the spirit to give light to the people, for they devote themselves to both their political leader and their divine god, thinking them as "quasireligious" (177). The general people visit the temple to show respect to divine potentate as they do for their king unlike the English people. Temple cult derived from Western Asia is not a part of authentic Hinduism which produces the devotee to create a welfare society. But the prevailing practice of Hinduism involves attaining the aspiration of everyday life. Hindu people attempt to amalgamate worldly prosperity and happiness and spirituality. Conversely, English spirituality lacks human affairs. In practical experience, "religion and civilization were still interwoven with each other in England" (180). The influence of democracy and industrialization makes their lives uncivilized. After all, it occurs for "forbidden ignorance" (180). Religion is for the general people in England, but it is observed in different conditions in India. Indian religion, the vibrant section, gets priority, not considering the "unhappiness of their people" (181).

\section{b) Atmosphere}

The writer's description of the atmosphere in the travelogue follows Hegel's triadic movement. He makes a sense that Indian's unrealistic sense is created for the weather of India. The temperature and light tempt them to leads a life in sleeping beauty; so warmth is necessary to arouse the spirit. This sleeping beauty is not visible in the day light of cold countries. Since Indian heat and light are hot and sunny, people in the cold country like the English Viceroy in India appear at dawn only. He notices the beauty of Qutb Minar at dawn, not at day light. The branches of trees become visible like fans. The outcome of light bears the testimony in architecture, and we observe the elegance of light in it. English natural landscape, along with architecture, shows an impression of solidity, but such beauty is absent in India. Things are as like as mirage. The light covers the Mogul building, in a disruptive way to show its visible existence with a "modicum of impressiveness" (20). Indian flowers with spectacular colors spread fragrance in the surrounding atmosphere of India. Indian landscape "tends to resolve into a silhouette" (21).
Though it is observed two dimensions, the Indian garden exposes itself as a "horticultural extension of the flat and linear Persian art" (22).

In other way, it is a matter of wonder that the cold countries have an experience of soothing dawn except during daylight. Thus, the tropical people find happiness since it is "impossible to be gay" (18). But the writer feels the optical effect or the reality of the third dimension when he is in India. What he notices French and English park is visible from his verandah in Delhi. English trees look like "paper-cut" (18). The branches of trees appear like sprouting flowers in France. The architectural grandeur molds Cambridge, Oxford, and Place Vendome. The flowers inflict to awaken the sensation of the plastic color in the painting. The English landscape moves round like "an into-the picture movement" (21). It gives a new sensibility to the outsider. The beauty of the country appears different, even the gardens in England reflect three-dimensional sense.

The writer wants to harmonize that this difference of these two diverse worlds reflects the "natural appearance of the visual phenomenon" (22). When we look at the East, it controls our way of seeing, "a rarefied way" (24), and when we are in the western world, "a concrete way" (24). This thinking goes on for the difference in reality, though the Eastern people call European cubes, in the same way the Europeans name Eastern a pack of cards,

\section{c) Behavior}

The writer also maintains Hegel's triadic sense of behavior to reach the absolute truth. During his visit, Chaudhuri sees that life in London is similar to a silent film. Though the public and streets places are crowded, no hustle and bustle disturbs anyone. The constant streams of people in the underground station and Oxford Street remind the writer of a "long line of ants going into their holes" (81). The silence or speechless situation is evident in common people's behavior in England. Besides, noise is an essential part of India to show cheerfulness. But life in England is "like a film of pre-talkie days" (82) because people walk in the underground station as the long line of ants what is different in the bazaars of India. So, the writer calls it "the eternal silence of these infinite crowds" (82). He does not hear any conversation in any place in England, even in the club, but all locations in India are "booming with talk" (82). The word 'silence' is a bizarre notion to the Indian. The places of public areas, worship, homes or roads signify the Indian way of life. Nirad Chaudhuri emphasizes that "...for us noise is as essential a condition of cheerfulness as is the warmth of the sun" (80). Physical closeness has a different vocabulary in India, "in the buses of Delhi, all of us make use of one another for bodily comfort" (81). The buses whir with conversations on topics of private and public. Chaudhuri 
names the coaches of Delhi "a microcosm of our national life" (83). Very subtly, he balances the dreariness of the English people's public behavior with the "comedie humaine'1" (84)- the large-heartedness of the Indians. There is a secret of English silence, which is for reserving energy to do work. It is useless to compare the talkativeness of Indians with it. This difference in the self-expression of the two countries is governed by the climate of the two countries. The Indian weather constrains the capacity of its people giving advantages of the vocal cords; on the other hand, the English people's self-expression rests on their activities. The writer tells this in the chapter titled 'Tell Me The Weather And I'll Tell The Man' which tells about to arouse curious speculation within Indians and the English. English weather is provoking and distrust, which has molded the English people's sensibilities. It forces them to be responsive to various changes in the environment and makes them immune to surprises, whether pleasant or unpleasant.

\section{d) Love for Money}

The Englishman's attachment to money is immeasurable. The writer reveals that English people's attraction for money is "reasonable and decent" (105). It is a country of easy money, "everybody was not only expected to pay his dues promptly and regularly but also, generally speaking, did so. In our society, the willingness to pay decreases as the capacity to pay increases" (102). The writer gives an analogy to show the level of their love for money- they are eager to have it as the wild animals show for their young. The attitude to money is wholly psychological, but not religious or others. The English people keep a shrine for "normal Christian worship" (106) but not a private sanctum of cash. But Indian people do so to worship a shrine of Lakshmi, a goddess of prosperity, as a sign of their devotion acquiring financial well-being.

Indian people's "religiosity covers every aspect of money-making, including the dishonest and violent" (106). But Christianity is not attached with financial interconnection directly. The religious attitude in India rests in economic affairs, which is a familiar affair, although the people consider themselves avant-garde. So India is, to all economists, El Dorado. Indian's connection with money is as same as lovemaking. But the English treat money smoothly, and they do not feel sad to be a part of the capital. They maintain morality in business. They think the "love of money to be enjoyed must be restricted" (109). On spending, it comes a different scene, "on this side there was as much assertiveness as there was secrecy on the other" (104). The English are of two types- the miser and the spendthrift. The controlling power is in the hand of the second one. Spending is highly taken as a positive urge and ideal, but frugality as the reality of expenditure. They aspire for pleasure to attain virtue. They have to spend but it gives them pain. But Indian people do not spend money in cold blood as English people do. To them, hoarding is a kind of satisfaction. But it is a kind of pressure for moderate people in England to spend money on their modern living, and it is a "temptation, passion or panic" (110) for the wealthy people.

English government and economists have notified English people to be cautious against spending habits because they maintain a hierarchy in spending. They continue it not for their standard of living but for being "style in living" (114) making them careless in their way of life. Surprisingly, unable persons to be casual are forced to pretend to be so. Those who are successful do not pretend to feel sore for their sartorial style. Then they compromise with this moral deterioration. The English middle-class shows uncomfortable attitude in a Bond-street shop. The difference is not for comparison, but it is a traveller's scrutiny into observation. The tourist Chaudhuri enjoys the situation,

I can hardly say how it gladdened the heart of a spendthrift in both principle and...my means...to find myself in a country in which spending was respectable. I liked the English people for their devotion to spending- 'That's the way the money goes'. (107)

At last, the writer, as an eye-opener, learns from their financial attitude that "the best use for money is to spend it on the good things of life" (114). It is a kind of thought which is an anathema to the Indian mind-set.

e) Love

Love is the basic inspiration of English people the same way as Indian people's money-making, which is a revelation, "in England, as indeed all over Europe, love seemed to be a primary motivation of human beings, a major occupation of men and women..." (109). Love shows the fundamental unity in England. But this sense is absent in Indian society because "love-making at first hand is virtually impossible" (115) since England the history of love in India is the source. Indian "deals with love from the literary end" (116). Love follows the passage of English literature to Bengali Literature, which is shown in life. It becomes delicate for this process of passing. Indians gather the experience of two kinds of marriage- legitimate marriage and love-marriage, a source of discontent for son's mother. Love after marriage becomes transient in the long run, "it is a marginal luxury, a fancy value, which is never taken into explicit account as one of the pleasures of marriage state" (110). Without love, they even lead a happy life without moorings of love. Due to comprehend the aspect of the English, he emphasizes the Indian attitude towards love. Conversely, it is evident that love in western society, an independent body, not a mere literary phenomenon, is "an easily observable activity (117). They expose their love without hesitation and want to exalt the mental and physical organs in lovemaking even at the time of exhaustion. Englishmen in 
lovemaking expose "their dignity and French-men their intelligence" (117) because the country is dedicated to safeguarding their freedom. The democratic behaviour towards lovemaking forms sensibility by making a romantic and idealized love between the two sexes' secret relationship, "the most significant movements in the evolution of sensibility, which has brought about the emergence of romantic and idealized love as a basis of the intimate relationship between men and women" (112).

However, "it is Europe's special contribution to the life of passion of mankind." (118). Love is treated as a biological term meaning that their family life and love pass through the same passage in western society. Love without family life is valueless in this society. Love is idealized and romanticized here. Their literature makes it more significant. The English unlike Indians take a frigid stance at the point of heart and tender feelings. In Hindu society, family life without love creates tiredness and boredom. Love even erroneous love transforms into "pity than repulsion" (119) in western culture. But Hindu society treats love on a moral basis and considers fidelity as the end of love. In Europe, man is the maker of any relationship, but a woman in India establishes the sense of faithfulness man has to oblige. However, many westerns do not comprehend the Indian marriage system and the value attached to it. But many Indian people perceive happiness in this marriage pattern. At this point, the writer is concerned with the virtues of the Indian marriage system. Chaudhuri astutely points out the difference in the two cultures with an actual perception, "in Europe the idealization of relations of the sexes was the work of man; in India or, to be more acute, in Hindu society it was that of the woman" (113).

The realistic matter is that anything is not beyond limitations. The failure of the western system is that making love passes into wild situation at the end, "which sends men and women out on a selfish chase after a will-o'-the-wisp" (120). To the writer, love is significant in human life to make life blessed. Besides, loveless life is equal to a tragic death inflicted misery on any other. The western male and female living together with satisfaction and love soon lose their happiness, which leads to the separation of each other quickly. The English deal with love with the abstraction of love, whereas Indians do so with more concretized in their matrimony. Romance in Eastern and love in western are not comparable to each other, because dissatisfaction and satisfaction make a harmony to each other by executing the formula- life plus love=life minus love though the writer is critical of Indian for developing this uprightness.

\section{f) Origin}

It is impossible to correlate England with the invaders having differences with Roman, Celt, Dane,
Saxon, or Norman. Besides, India is correlated with Scythians, Aryans, Huns, Muslims and British. English people belong to different features in speech and behavior above all in appearance. To the writer, a clerk of Indian high officials is as the working people in Hyde Park. The writer sees the common traits without any differences whenever the writer meets several types of people of different professions. "They all conformed to what to my unpracticed eye seemed to be the uppermiddle-class type, to be distinguished from the lowermiddle-class, which I could also recognize" (72).

Since everyone thinks that India, "more a continent than a country" (73), not a country, is the amalgamation of regional cultures and many languages. The heterogeneity in their dress, appearance and attitude do not expose any explanation since deeper forces are active. But it is shown that anybody finds that weather and climate make different modes in the West and the East. The cold weather forces the West to execute an enormous will-power. The writer does not find uniformity in mass people, unlike India. Indian people observe two kinds of people- the common people without pretension and others one middle-class. Almost all women in England wear regular clothes without a beautiful face. But fair complexion is the main aspect of all Indian women's physical beauty. There are two types of women- "who are considered beautiful and consider themselves beautiful" (77) who are unequal. But they do not accept other's negligence by overlooking them. Unlike English women with a natural appearance, the dark complexion woman decorates them artificially. The fashionable Indian women dressed themselves in excess. The writer exposes the real human physical beauty found in art from the West "its amazing nudes" (78).

\section{g) Synthesis}

In A Passage to India, Dr. Aziz's acquaintance with Mrs. Moore in the mosque, mother of City Magistrate Mr. Heaslop is the first step of making as a friendship between Indo-British. The similarity in their personal life being widow and widower and having three children- Aziz's Ahmed, Karim, and Jamila, and Mrs. Moore's Ralph, Stella, and Mr. Heaslop- smoothes the path. This similarity makes them curious about each other and advances their relation. The actual communications between them make Aziz feel her as "an Oriental" (45) making a synthesis between them. In the danger of Aziz's jail, she declares his innocence. Moore alienates herself from the court and all other happenings related to Aziz after the expedition. She only wants to leave the place immediately to avoid trial, marriage and Indian hot weather, and does not want to face all these evil happenings to Aziz. She feels remorse for her failure to fulfill her dream to make Aziz happy and alienate herself from India by catatonic withdrawal. At last, she detaches herself eternally from the world by 
being dead. Reminding her, Aziz lets Adela off the paying. Whenever he sees Mrs. Moore's son Ralph Moore at Mau in India, he becomes overwhelmed with him from his heart because "with the name that is very sacred in my mind namely Mrs. Moore" (314).

Mr. Fielding, principal of a government college, is the only person who is gay to be with everyone who they are- Indians or British, and Mrs. Moore and Adela's amicable attitude towards Indians make a smooth path of synthesis. Fielding's understanding is that goodwill and well behaviour can be a way of integration since "God has put us on the earth in order to be pleasant to each other" (70). To him, the world "is a globe of men who are trying to reach one another and can best do so by the help of goodwill plus culture and intelligence-a creed ill-suited to Chandrapore" (80). To contact each other without racial feeling through the process of goodwill, culture, and intelligence can bridge them as he does so. His first meeting with Dr. Aziz is with a language, "please make yourself at home" (81), and his "unconventional behavior" (81) makes a smooth path to be close with Dr. Aziz. They build an intimate relationship because they know "only good of each other" (82) and they can "afford to dispense with preliminaries" (82). Though Aziz's speech rattles during their conversation and he goes back in history, Fielding as an optimist does not feel irritation for their relationship build-up, only thinking over "what is friendship without confidence?" (268). Mitigating any disagreement by pointing out a fact "some misunderstanding" (85), his willingness to integrate with the Indians is to avoid the wrong idea about India. Set aside the politics of the British in India, he makes himself a reliable person to understand Aziz. Indians are fascinated with the kindness of Mr. Fielding for visiting them. Being intimate, they are "beginning to trust each other" (123). He places himself in India like that everything in the world is dying, but in the dying place they still think over "the existence of a beneficent Providence" (123). He retains his view of understanding another individual more to mix up with other civilizations like Indians. After the expedition, Fielding understanding Miss Quested's "some hideous delusion" (177), claims of Aziz's innocence to show his genuine friendship and humanity. Though "nothing embraces the whole of India, nothing, nothing (156), as Edward (2002) says that "a cave is a capsule of nothing: only humanity introduces whatever meaning it has".

Holding the brotherhood concept, "men are my brothers" (128), Aziz considers Fielding as his brother because of his behaviour even if he does not do that. So, he shows his wife's photograph to him. His wife can meet his brothers though he believes in the purdah. Fielding regrets that the world's people would behave like this; there would have no other purdah or rift between anyone. Aziz is very much pleased with the news of Fielding's marriage with Stella, Mrs. Moore's daughter. Though Aziz declares their impossibility of friendship during British Raj in India having a gap between them, Fielding's realization of power and integrity of character can turn the difficulty into possibility. Tayeb (2004) says that Fielding out of high principle and human understanding "stands out as the staunchest adherent of cross-cultural friendship and the wisest observer of the blind bigotry and mutual lash of racial prejudice and hatred." Through the image of cobra in the last part of the novel when Fielding and Aziz are riding, Forster expresses a hope of their synthesis which typifies as one of the roles of liberal humanism irrespective of race, belief, and gender. Kennard (1973) says that "at the end of the novel Fielding and Aziz, the representatives of East and West, separate as do Dickinson and the holy man. East had not met West, but at least they had shaken hands across the gulf."

With atonement and confession, Adela withdraws everything regarding accusation towards Aziz during the trial. At last, Aziz appreciates her for her boldness, which makes Fielding happy. Though the English have to live twenty-year to know about India and Indians because India is a place of wonder, language becomes an integral part of them to express appropriately. Adela is delighted to find Englishspeaking people in the Bridge Party, and Fielding is so much overwhelmed with the liveliness of the young generation's accent of the English language though they change their emphasis. The writer mentions the educated Indian who creates a new social outlook for communicating with the English. Thus, he creates a bridge of harmony in this binary to generate an entity amalgamating the two as the English's attempt to organize the Bridge Party creates a platform of the integration of Indo-British "to bridge the gulf between East and West" (49). White (1953) unearths that "if multiplicity is the fact, unity of some sort is the desire. The first kind of oneness affirms and ratifies the differences and separations natural to life, the second attempts to embrace and to reconcile them by goodwill, sympathy, kindness, and love".

The opposition in lifestyles, thinking, and cultural differences between Anglo-Indians and Indians in this novel is for the relation of the colonizer and colonized, ruler and ruled. So, the conflict in their integration is evident in their way of life. But the whole set of negations in the novel suggests the possibility of affirmation. Thus, we see that the individual attempt to reconcile the conflict without the support of the central point finds fruitless at the end of the novel for the ruler and the ruled condition. But there is a hope of regaining reconciliation by proper integration, as we see in Dr. Aziz and Mrs. Moore, which leads to making a bond with Ralph Moore as a sign of humanity. Moreover, genuine feelings and understanding of kindness can turn the rift into a bonding as we see between Fielding and Dr. Aziz, though reconciliation appears in the negative platform. 
On the other hand, there is a constant swing between his country and the travelled country in the first half of the travelogue. The contrasts and comparison are evident but not severely exposed. But it is very subtly done. The author does not degrade the origin of his country at any point; even he does not exalt England. But many think that he shows different views of India and England in every chapter of the book giving the superiority of any one of them. But he authentically synthesizes this difference by showing actual reality. Through his knowledge of western culture from reading books, he sometimes unfolds superiority of English on Indians to express the fact to remove the oppositions. He wants to make a bridge between them by accepting the real sense regarding Indians and the English.

The writer narrates how Indians can encounter with the British by comparing and contrasting many aspects of life in India and England. As a part of humanity and with the technique of praising, which is real in India and England, he takes an initiative to create a passage of proper integration between them. Though his position in his country is oscillating for debasing his country, he exposes what he witnesses during his travelling. The popular myth of oppositions- India and England makes a proper admixture of the popular myth of the opposition in Nirad C Chaudhuri's travelogue A Passage to England. To think of the East and the West as one body of the globe anyone finds a soothing explanation. Physically, it is impossible to resemble them in one trait for being part of two separate entities of the world. There creates opposition for being part of two different independent countries around the globe. This separation confirms an opposite sense in their attitudes, lifestyles, cultural behavior, values, and habits. Once again, he admits that climate and weather shape the different individual behavior of the East and the West. If anybody from either world tries to amalgamate them in one trait, it "would be a suicide revolt against nature" (26).

\section{Conclusion}

By the comparative analysis of these two books, it is seen that since in binary opposition the first one governs the second one, Chaudhuri in his book depicts the governing position given to England, not India in almost every pattern of life. But it is seen that as Derrida says, the center does not belong to static; the writer's superior placement of Indian family life and generous behavior over the English set of life bears the hope of changing the position of center. Indians willing to adopt all things from England what is right make them equally superior which will be the absolute truth, as Hegel exposes in his triadic movement. Since conflict is unavoidable for the binary oppositions of the English and Indians and it arises in the binary mind holding contrastive practices for separated circumstances around the globe, mutual recognition and understanding can overcome their resistance by displacing differences.

\section{RÉFÉRENCES}

1. Abrams, M. H. and Harpham, Geoffery Galt (1929). A Glossary of Literary Terms. UK: SS Publications, pp. 79.

2. Edwards, Mike (2002). E. M. Forster: The Novels. New York: Palgrave, pp. 171.

3. Kennard, Jean E. (1973). A Passage to India and Dickinson's Saint at Benares. Studies in the Novel, 5, (4), pp. 417-427.

4. Macey, David (2001). The Penguin Dictionary of Critical Theory. New York: Penguin Putnam Inc, pp. 366.

5. Tayeb, Lamia (2004). The Inscription of Cultural Bafflement in E. M. Forster's A Passage to India. Interdisciplinary Literary Studies, 6(1), pp. 37-59.

6. White, Gertrude M. (1953). A Passage to India: Analysis and Revaluation. PMLA, 68 (4), pp. 641-657. 